\title{
Metaphysical Discourse and the Logics of the Absolute
}

\author{
Aleksandr Kulieshov ${ }^{1}$ \\ ${ }^{1}$ Cherkasy State Technological University \\ 460 Shevchenko Boulevard, 18006, Cherkasy, Ukraine
}

DOI: $10.22178 /$ pos.56-5

LCC Subject Category: BD95-131

Received 20.02.2020

Accepted 27.03.2020

Published online 31.03.2020

Corresponding Author:

klshv2014@gmail.com

(c) 2020 The Author. This article is licensed under a Creative Commons Attribution 4.0 License @) (1)

\begin{abstract}
The article deals with the problem concerning the language of metaphysics. Metaphysics is understood as knowledge about the world as a whole. It is argued that such a perspective needs specific language tools for the description of metaphysical reality. The principal characteristic of the terms of the language aimed at describing the world metaphysically is their ultimate abstractness. It is stated that this abstractness not just corresponds but coincides with the ultimate simplicity of metaphysical reality, that is to say, the reality of the world as a whole. The analysis of the ultimate reality or the absolute leads to the conclusion that both such reality and its depiction is ruled by a special logic different from what is conventionally considered to be logical. Elements of this logic are the ultimate abstractions. As it turned out, logical laws do not apply to extremely abstract objects, first of all, the law of contradiction. In the logic of the absolute, mutually exclusive statements point both to the same and not the same reality. The analysis shows that this is not the dialectical logic of contradiction and denial, it is the logic of the consistent unity and coexistence of identity and difference. The use of identities and differences in their ultimate sense allows us to determine the basic concepts of a metaphysical description - being, existence, the existing, difference, identity. Basic concepts serve as a necessary and sufficient basis for a complete metaphysical description of the entire existing, that is, the world as a whole. Going beyond the basic concepts, we, however, move from the logic of ultimate reality to the usual logic of empirical (physical and mental) reality.
\end{abstract}

Keywords: metaphysics; logics; ultimate reality; difference; identity; the logic of ultimate reality.

\section{INTRODUCTION}

At the beginning of the 21st century, metaphysics once again, as in older times, is seen among the respectable areas of knowledge. Metaphysics traditionally is positioned as the most general and fundamental description of that reality, in which the readers of metaphysical texts usually discover themselves. The possibility of such a description is problematic due to its extreme abstractness. The problem lies within the correlation of the metaphysical description purpose and its linguistic means. To solve the problem is to find a certain minimal set of language tools that can describe everything existing or to explain the impossibility of finding such tools. In other words it goes about the basic, most elementary and, at the same time, the most effective language of metaphysics.
It is one of regularly discussed themes in nowadays analytical philosophy. Various opinions concern the possibility of semantically complete language $i$. e. the language which terms and statements refer not to other terms and statements but to extralinguistic reality. The situation is fairly accurately characterized by Cord Friebe noting that within analytic metaphysics the debates always come down to the question "whether there really is a substantial ontological distinction, or whether, in fact, the dispute is merely verbal" [3, p. 5]. The first position is in most cases called realistic, the second has a number of names depending on how deep is the departure from realistic stance. One can say about "deflationary intuitions threaten the robustly realist approach" [7, p. 3], about superficialism which argues that in metaphysical debates "very 
often disputants are talking past one another, on account of having attached different meanings to the key terms" [4, p. 213], or dismissivism including antirealism, according to which metaphysical expressions do not have a determinate truthvalue, semanticism, according to which the differences between metaphysical expressions are purely verbal, and epistemicism, according to which metaphysical expressions have little justification for being either true or false [1, p. 3942]. The point of anti-realism in a broad sense is, in D. Chalmers' words, that there are no objective answer to the question of 'What exists?' [2, p. 77].

Some answers to this question surely do exist and are explicit. Whether they are objective is not explicit at all from the beginning, it is rather the matter of belief. The justification of this belief is in that it is the only starting point for its justification. We must adopt one or another variant to follow it till we come to a more clear and evident result.

Our choice here is realistic metaphysical language. Some arguments in its favour as well as its more detailed depiction can be found in T. Sider [9] and T. E. Tahko [10]. T Sider, in particular, proposes his variant of structural metaphysics. "The heart of metaphysics is the question: what is the world ultimately, or fundamentally, like? And fundamentality is a matter of structure: the fundamental facts are those cast in terms that carve at the joints" $[9$, p. 5]. It is worth saying that fundamentality is really a matter of structure, but the structure itself is not fundamental. It is too complex a phenomenon demanding some not evident preconditions.

One more conception the author of this article is sympathetic with is that of J. M. Mulder [8]. It marks a certain return to Aristotle by overcoming the dichotomy of realism and antirealism. The essence of this move is in not separating "reality as it is in itself and reality as it is for us", in destructing a fundamental gap between them [8, p. 81]. This idea seems to be not only true but extremely productive.

Still the question of implementing realistic principles in searching the elements of a metaphysical language for the description of everything that exist leaves to be open. To single out such a minimal set of the language of metaphysics elements is this article's objective. (One can learn more about the author's conception in $[5,6])$.

\section{RESULTS AND DISCUSSION}

Let's begin with clarifying the subject matter of metaphysics. It is acceptable to think that this is the world as a whole (the World, to be more precise). The concept of the whole requires specification. The whole here should not be understood as something that has boundaries. The whole in our understanding is that which has something in common, that which stands out or is constituted by the common. The mentioned commonality is obvious - it is the fact of everything's existence which determines its belonging to the World (whatever we mean by existence). No doubt that existence is a term equivalent to belonging to the World; speaking of existence, we actually say that something belongs to the World. This is one and the same. The World is clearly defined as all that exists.

So, we can talk about the World as a whole regarding it to be a real object. It is important to say also about the nature of its reality. Obviously, the World as a whole is not a physical reality. This is an extremely significant and far from trivial statement. The fact is that the concept of physical reality is derived from the concept of the world, but not vice versa. No basic physical object or a system of such objects includes the world as a whole, in other words, as everything existing. Nor is the World a psychic reality either. The foregoing applies to any of the realities known as subjects of specific sciences (social, biological, virtual reality etc.). Let's say that the World as a whole is a special, peculiar reality. It is possible to limit its designation by indication to its peculiarity. But it will be appropriate to call it metaphysical reality.

Obviously, the World can be described as an absolute reality in all respects which are usually meant. The absoluteness of the World follows from its uniqueness; since it covers everything that exists, there is nothing to compare it with. First of all, it follows from here that world reality is maximally complete and general, allencompassing. Secondly, we can talk about the ultimate simplicity and abstractness of world reality, since any complexity requires a ground for itself, which the World as a whole does not have. Due to ultimate simplicity of world reality, the concept of physical laws does not apply to it. There are no laws at all, since there are no constitutive connections between individual partial objects belonging to this reality. Connections in absolute reality, if we can talk about them, are also absolute - extremely abstract and universal, 
which means that they are simple and indistinguishable.

Absolute reality is also not a subject to the laws of conventional logic. It is generally accepted that logical laws are more general and abstract than empirical (physical) ones. But they also express stable and necessary connections between objects, for example, connections of presence / absence, correspondence / contradiction. Such connections are not found in absolute reality. There is no usual logic for it by which it would be possible to connect the selected objects (and therefore, explain them).

It doesn't mean that absolute reality lacks any sort of multiplicity. Being ultimately simple and abstract this reality goes beyond the very juxtaposition of the opposites - simplicity vs complexity, abstractedness vs concreteness. Either of them is not a denial of another. That which is ultimately simple is just simple and is not noncomplex in addition to it. But paradoxically this absence of non-complexity denial leads to absolute reality being both absolutely complex and simple. It is simple from the point of view of our simplifying efforts based on empirical reality's complexity. But it should look otherwise from the opposite point of view. The real absolute reality is, probably, still more undefined towards simplicity / complexity opposition.

In the long run, the simplicity of absolute reality appears to be not quite simple and can be depicted in different terms. The terms have to be combined and disconnected, which means that some kind of logic (as a movement of thought) is present here. One should assume that here we encounter another kind of logic, not the logic familiar to us in its forms that have been established for many centuries. Imagine a logic in which the basic logical laws are not valid. This is a logic in which the laws of identity, contradiction, excluded third, sufficient reason do not apply. These laws imply a clear distinction between objects and are effective only when it is possible to separate and contrast objects of thought. In absolute metaphysical reality there is no such distinction. Its fundamental specificity is that we cannot, while thinking over it, compare and contrast different objects of thought. Everything within our mental picture merges and separates, slipping away from us, we can neither completely separate, nor completely merge imaginable objects. This is because they do not have the outer ground for complete separation or contraposition. They are too simple and abstract for this.

The closest analogue of the logic indicated here from the history of philosophy is Hegel's dialectical logic. This is the logic of contradiction which is inherent in every object of thought. The dialectical contradiction is contradictory, so it comes into identity and returns back to itself. Something is directly something contrary to itself. There is a relation of negation between something and its another: one denies the other, and the other denies the first. Something, therefore, is neither itself, nor something else, but turns out to be the third something (a synthesis of thesis and antithesis). Hegelian logic is metaphysical in terms of its difference from traditional logic, but has serious flaws in terms of its relevance to the tasks of metaphysical description. The main flaw of dialectical logic is that it is based on thinking. But the world as a whole is not a thinking (as well as it is not physical being). The world as a whole is a thinking, as far as it does not differ from being, or it is being that does not differ from a thinking indistinguishable from being. Therefore, the world is not only a thinking and not only being; it is something common in being and thinking. Since being is more abstract than thinking, the common in being and thinking is being. The world is being, which is not only being. But the world is not a thinking, insofar as the latter is different from being. The difference between thinking and being is that the first objectifies its content. It makes the objects out of thoughts. For example, thinking sets before itself two objects that are mutually exclusive. And it becomes seen that in a sense this is one object. Thinking carries out a game of transitions from one to another and vice versa, makes mutual denials. But for this, thinking must remain only thinking. The World as a whole is Being that does not objectify itself for itself, but directly is also something else.

Everything that exists does not deny itself and does not contradict itself. It is something one and is something else together. And yet the world is only one thing. Moreover the world is only something other than the world. There is no contradiction in these contradictory statements. There are no transitions of thought, discrimination or identification. One does not deny the other and does not deny itself.

To summarize what has been said. In the logic of the absolute, we can only talk about what is. At the same time contradictory statements are 
permissible and even obligatory. Contradictory statements do not express contradictions. Once again: there is one and there is another. The world is one and the same; the world is something other - these statements simply coexist without contradicting or denying each other, without passing into each other.

The ultimate existential determinants, therefore, are identity and difference. They are also logically compatible in absolute logic. The following statements are equally acceptable. Being is identity. Identity and being are one and the same. Being is different from its identity with itself. Being is difference. Being is different from the difference itself and from being's difference from difference. And so on. To be one and the same and to be something different from another is simply to be. So there is no difference in it. And there is an absolute undeniable difference. Still this is not a contradiction.

Absolute logic allows the difference indistinguishable from identity and, however, distinguishable from it. For the World as a whole, therefore, that logic is relevant, the elements of which, in addition to being, are identity and difference. In the language of this logic, difference and identity play the role of connectives creating logical formations (statements). Connectives link terminal terms (the role of which is played by being and its derivatives). Any combinations are allowed. They do not exclude each other, but implement new coexisting parts of reality. The intensional differences in the semantics of the language of absolute logic coincide with the extensional ones - the same thing expressed in different senses is different extensionally (the resultants are mutually complementary).

To the statements formulated earlier, one can add some more. Being is identical to Being. Being is different from Being. Being (which is only) identical with Being is identical with existence. Being (which is only) different from Being is identical with that which exist. The existing (as Being) is identical with existence. And vice versa. The existing (as such) is different from existence. And vice versa.

Such is the logic of ultimate abstractions - being, existence, that which exists, identity, difference. It is of no surprise that, reaching the limit of abstraction, the concepts begin to coincide. Meanwhile being the results of long and gradual abstraction, the concepts do not lose their differences. But speaking of ultimate differences, it is vastly important to understand that these differences are immediate; concepts differ not by something in them, but only by themselves. The direct difference is, on the other hand, the direct identity; concepts (remaining concepts, not turning into a concept) coincide, flow one into another. Everything at the ultimate level of metaphysical reality is found in everything and everything is different from everything. Nevertheless, there are no contradictions and denials (which had been pointed out by F. Bradley, who tried to grasp the essence of the Absolute reality). Thus, mutually exclusive objects which coexist (no matter how paradoxical it may seem) are at the ground of the world. Coexisting concepts expand logical and metaphysical reality.

However, this is not the logic of being and nothingness - everything happens within the limits of Being. It must be understood that nothingness is a purely logical term that does not refer to anything within the world.

Let us once again draw attention to the fact that ultimate abstractions are not only conceivable. They necessarily and always include extralinguistic reality. In a certain aspect they coincide with reality. Reality as something ontologically simple is indistinguishable from logically fully abstract conceptual content. The image of Being as such (if we have reached it) is Being itself from a certain point of view. It also has a sensory side - a sense of being that coincides (although not quite, but only by content) with pure being.

It is reasonable to use the named ultimate abstractions: being, existence, that which exists, identity, difference as the basis of a metaphysical description. At our disposal there are elementary entities (and the corresponding categories of thinking), on the basis of which a complete metaphysical description of the world becomes possible. The specified base of the metaphysical description is necessary. Ultimate abstractions, coinciding, in a certain sense, with being and only being, ground themselves and do not require anything else for their grounding. The mentioned base is complete, since it is obvious that there are no other ultimate abstractions coextensive with being. It is also sufficient - there is nothing in the world that cannot be reduced to these categories. It represents both the basis and the product of logical relationships. We can say that this is what enters into logical relations as their non-logical ground. On the other hand, this is what logically grounds itself. Thus, illogical ground turn out to 
be logical. If you look at the subject from the ontological perspective, then the reality described by the ultimate metaphysical categories turns out to be both the basis of the existing and all existing itself.

Note that the logical base which have been defined coexists with a superstructure that is logically negative in relation to the base. This superstructure excludes the base and coexists with it. The logic of the absolute limit implies something not ultimate, impossible from the point of view of the limit, but coexisting with it in the logic of the absolute limit. The limit as the existing is identical with its own not-the-limit, i. e. with something different. In this aspect it is just the difference (or differing) of itself and not itself. At the same time, the limit exists as the limit of not-the-limit. In not-the-limit reality in a logical sense, the opposite to what it is in a limit reality is true. We go through the looking glass out of ultimate reality or, conversely, exit the looking glass into the familiar, empirical world. Here differences are only differences and identities are only identities. Something different cannot be identical and vice versa. Reality breaks up into separate objects that do not penetrate each other (at least completely). Mirroring the ultimate reality, the empirical world is ruled by the usual laws of logic, there separately exist an object, objects, and their aggregates, forming in whole the physical and mental world that is familiar to us.

\section{CONCLUSION}

So, metaphysical reality was looked over in the article. It has been argued that it should be understood as the reality of the world as a whole. It was stated that it can only be depicted using a special logic - the logic of ultimate reality. Elements of this logic are the ultimate abstractions. As it turned out, logical laws do not apply to extremely abstract objects, first of all, the law of contradiction. In the logic of the absolute, mutually exclusive statements point both to the same and not the same reality. The analysis showed that this is not the dialectical logic of contradiction and denial, it is the logic of the consistent unity and coexistence of identity and difference. The use of identities and differences in their ultimate sense allows us to determine the basic concepts of a metaphysical description - being, existence, the existing, difference, identity. Basic concepts serve as a necessary and sufficient basis for a complete metaphysical description of the entire existing, that is, the World as a whole. Going beyond the basic concepts, we, however, move from the logic of ultimate reality to the usual logic of empirical (physical and mental) reality.

\section{REFERENCES}

1. Bennett, K. (2013). Composition, Colocation, and Metaontology. In D. Chalmers, D. Manley, R. Wasserman (Eds.), Metametaphysics: New Essays on the Foundations of Ontology (pp. 38-76). Oxford: Clarendon Press.

2. Chalmers, D. (2013). Ontological Anti-Realism. In D. Chalmers, D. Manley, R. Wasserman (Eds.), Metametaphysics: New Essays on the Foundations of Ontology (pp. 77-129). Oxford: Clarendon Press.

3. Friebe, C. (2014). Categoricalism Versus Dispositionalism: A Case Study in Metametaphysics. Journal for General Philosophy of Science, 45(S1), 5-15. doi: 10.1007/s10838-014-9265-5

4. Hawthorne, J. (2013). Superficialism in Ontology. In D. Chalmers, D. Manley, R. Wasserman (Eds.), Metametaphysics: New Essays on the Foundations of Ontology (pp. 2013-230). Oxford: Clarendon Press.

5. Kuleshov, A. (2019). IAzyk metafiziki problemy i resheniia [The language of metaphysics: problems and solutions]. Scientific Discussion, 1(36), 3-11 (in Russian)

[Кулешов, А. (2019). Язык метафизики: проблемы и решения. Scientific Discussion, 1(36), 3 $11]$.

6. Kuleshov, A. (2019). Nachala metafiziki [Beginnings of metaphysics]. Stavropol: Logos (in Russian) [Кулешов, А. (2019). Начала метафизики. Ставрополь: Логос]. 
7. Manley, D. (2013). Introduction: A Guided Tour of Metametaphysics. In D. Chalmers, D. Manley, R. Wasserman (Eds.), Metametaphysics: New Essays on the Foundations of Ontology (pp. 1-37). Oxford: Clarendon Press.

8. Mulder J. M. (2012). What Generates the Realism / Anti-Realism Dichotomy? Philosophica, 84(1), 5384.

9. Sider Th. (2013). Writing the Book of the World. Oxford: Clarendon Press.

10. Tahko T. E. (2015). An Introduction to Metametaphysics. Cambridge: University Press. 